\title{
Effects of Self-encouragement Programs for Children from Low-income Families at Local Children's Centers
}

\author{
Eun Sook Choi ${ }^{1}$, Mi-Na Lee ${ }^{2}$ \\ ${ }^{I}$ The Doctor's Course, Department of Human Service Education, Kwangshin University, \\ South Korea,focusreading@daum.net \\ ${ }^{2}$ Professor, Welfare Counseling Convergence Department, Kwangshin University, South Korea, \\ Imn4780@naver.com
}

Corresponding author: Mi-Na Lee

\begin{abstract}
This study focused on self-encouragement programs for children from low-income families at local children's centers. To this end, a self-encouragement program was conducted so that people could find grateful moments and strengths in their relationships with others and practice positive relationships. The subjects of the study were 13 low-income children from third to sixth grades (eight males and five females) at a children's center in District B, C, Jeollanam-do for 12 weeks. The study looked into the area of support including the cognitive, emotional, and behavioral domains. In the cognitive domain, people were made aware of the meaning necessity, and the effect of encouragement. In the emotional domain, they were encouraged to find the heart of encouragement in the surrounding environment and situation and express positive emotions. In the behavioral domain, the encouragement of the environment was concretely practiced and expressed so that positive emotions could be directly experienced. As a result of the study, the participants, through the self-encouragement program, were effective in self-resilience and social support to cope more healthily in stressful situations. In other words, the more social support they received through the self-encouragement program, the more they felt psychological comfort. This reveals that the self-encouragement program has become a meaningful activity to find various situations and environments that can encourage children rather than resent their current poor environment, and to practice encouragement in their daily lives.
\end{abstract}

Keywords: Local Children's center, Self-encouragement Program, Encouragement Diary, LowIncome Children, Promotion of Happiness

\section{Introduction}

Humans make constant efforts to hope, want, and live a happy life. This can be approached from the perspective of positive psychology, and by studying the subjective psychological state experienced by humans, away from past experiences and suppressed problems. Research on the positive characteristics and strengths that humans feel is being dealt with in various ways in studying positive psychology. In particular, encouragement is used as a way to improve mental health and is an important subject of positive psychology to change into positive emotions[1]. People who take a positive approach feel satisfied when subjective encouragement is the basis in their situation. This means that children in lowincome environments, where parental environment and poverty appear as absence of parental roles, experience psychological difficulties compared to ordinary children and face difficulties in human life.

Received: September 22, 2021; $1^{\text {st }}$ Review Result: November 8, 2021; $2^{\text {nd }}$ Review Result: December 23, 2021 Accepted: January 29, 2022 
There are many economic and emotional difficulties at home and are exposed to personal and psychological risks, which are affected by childhood development[2].

From point of view, it is reported that low-income children have a relatively high degree of internal emotional problems and aggression such as depression and anxiety[3]. In addition, economic difficulties can have more serious effects on children than adults and negatively affect task achievement to develop in childhood[4]. In particular, Research on positive psychology is needed in previous studies on lowincome children, and more active measures should be prepared as it is an important time to promote happiness for them. The poor environment of the low-income class may not be easily changed, but the subjective interpretation and life satisfaction felt by the children themselves are different. Encouragement is encouraging and is an important variable in focusing on psychological maturity.

It can overcome negative situations, switch positive thinking, and augment social and cognitive resources. Although there is a lot of personal psychological approach and interest in encouragement, research on self-encouragement programs needs to be conducted. Research on promoting life satisfaction and optimism are effective variables for encouragement[1] and research on the development of potential and mental health for low-income families are needed. These can support the emotional development of low-income children, and a self-encouragement program is needed to promote happiness in childhood. Until now, the research includes an encouragement program for facility protection children[5], an effect study[6], an encouragement activity study for adolescents[7], a meditation program effect for middle school girls[8][9], and an encouragement program[10] using picture books for elementary school students. Previous studies on self-encouragement programs for lowincome families are very insufficient.

This study aims to develop and apply a self-encouragement program for low-income children, find out their effectiveness, and examine the responses of participants.

The contents of self-encouragement are shown in [Table 1].

[Table 1] Self-encouragement

\begin{tabular}{|c|c|}
\hline Component & Contents \\
\hline Positivity & Value yourself \\
\hline Responsibility & Take responsibility for your own choices \\
\hline Reliability & Trust your own evaluation \\
\hline Vessel & Speak up and have courage \\
\hline Pleasure & Ability to take initiative and have fun \\
\hline Social interest & Social interest increases through community participation \\
\hline
\end{tabular}

To this end, basic data were pre-interviewed by ten local children's center workers from October to December 2020, and based on their understanding of encouragement for low-income children, they were organized by referring to the questionnaire of Yoo Sun-jin[11].

In addition, the composition and direction of the self-encouragement program were set, and it was actively reflected in the demand survey and specific contents. Therefore, the self-encouragement program can help low-income children when they recognize the situation and object of encouragement and when actions are accompanied as positive emotions and expressions. It is possible to adapt flexibility and improve satisfaction with life in the environment where children are located.

First, for the process of the self-encouragement program, the encouragement of low-income children was referenced by real life and developmental factors. Second, the encouragement program is a group targeting the whole, but it is composed of individual and partner activities and groups so that group dynamics are not negative due to the large number of people. Third, after the encouragement program 
theory activity, semi-structured video viewing and activity sheets were used.

In the last session, children were asked to present self-directed encouragement diaries and feelings to achieve program goals. The research problems based on the necessity of the above research are as follows.

First, what is the composition of a self-encouragement program for children at local children's centers?

Second, what is the effect of self-elasticity, subjective well-being, and social support through selfencouragement programs?

\section{Research Method}

\subsection{Selection of Research Subjects}

The subjects of this study were 13 low-income children from third to sixth grades (eight males and five females) at the C Regional Children's Center in B-gun, Jeollanam-do, who gave their consent to participate in this program.

[Table 2] shows the characteristics of participants in the self-encouragement program.

[Table 2] Characteristics of Research Subjects

\begin{tabular}{|c|c|}
\hline Agency & B Regional Children's Center \\
\hline Grade & Elementary school 3rd, 4th, 5th, 6th grade. \\
\hline Gender & Boys:8, Girls: 5 \\
\hline Total & 13 \\
\hline
\end{tabular}

Until now, studies have shown that low-income children have been provided with various programs, but there is a lack of self-encouragement programs that can promote positive factors.

\subsection{Program Overview}

Considering the environmental factors of parents, schools, and friends to which low-income children belong, the self-encouragement program consisted of various activities that focused on emotional and behavioral areas rather than cognitive areas. As for the content in the cognitive domain, the meaning, effect, and nececssity of gratitude were recognized, and the emotional domain was to find gratitude in the environment or trivial situation surrounding others and connect it to words expressing positive emotions. Then stroke your body with your hands, appreciate yourself and express your gratitude to yourself. Focusing on expressing gratitude in the behavioral area, family, friends, and community thanking targets were found to experience positive emotions by directly expressing gratitude for the participant's environment, such as letters, notes, thank bookmarks, thank gifts, and thank diaries.

\subsection{Development of Self-encouragement Program}

The procedures for developing self-encouragement program in this study are as follows.

First, a demand survey was conducted through interviews with ten current local children's center workers (five center heads and five social workers) between October and December 2020. Second, a preliminary program was organized for one month from January 2020. Second, A preliminary program was organized for one month from January 2020. In order to objectively review the composed program, three theoretical experts (doctors) and two clinical experts (doctors in counseling) verified the program validity, and the preliminary program was revised and supplemented. Third, program composition, educational content, and activity method for each session of the program were selected for one month 
from March 2020, and specific activities were organized based on the selected contents. Fourth, the application stage of the program took place once a week for 12 weeks from April to July 2020. In this process, the subjects of this program were selected through experimental design.

\subsection{Contents of Each Program Session}

This study developed a self-encouragement program with a total of 12 sessions. In the introduction part of the first session, a sense of trust and intimacy between group members was formed through an understanding of gratitude, group rules, and self-introduction through nicknames through the 'conditions of thank' video. After completing the self-encouragement program, they imagined themselves changing and expressing their efforts to achieve their goals in detail.

The second session aimed to share gratitude through other people's lives. In the introduction part of the first session, a sense of trust and intimacy between group members was formed through an understanding of gratitude, group rules, and self-introduction using nicknames and the 'conditions of thank' video. find the experience of helping someone, and share their feelings about the audit method expressed by the person who received their help. The reason for not expressing gratitude, the best expression of gratitude he received, and what he could express his gratitude well were explored.

In the third session, the goal was to find one's representative strengths, learn how to think optimistically, and recognize oneself positively. In the introduction part, they were asked to think about gratitude through the "Choi Sung-bong" video, shared their strengths, strengths found by friends, and experiences in which their strengths were demonstrated in their lives. They looked for trivial things to be grateful for, wrote a relationship map surrounding myself, and recalled and expressed what they were grateful for.

In the fourth session, the goal was to understand one's feelings, learn how to express them in language, and communicate positively. In the introduction part, they shared their thoughts on gratitude through the "Thinking Pre-Forgiveness" video, explained their choice of emotion cards with gestures, facial expressions, and words, and understood their emotions through games that the other person guessed. After completing the emotional pizza using the emotions they usually use, they were able to examine the situations in which three emotions mainly used occur. Thinking of situations or events that upset them, they were asked to express what they wanted to say and hear to and from the other person. They thought about it from the other person's point of view and became the other person to tell their story. In the end, a letter of forgiveness was written to the object who was upset (disappointed) with the other person.

The fifth session aimed to understand one's feelings, learn how to express them in language, and communicate positively. In the introduction part, through the "Lena Maria" video, they shared their thoughts on gratitude and thought about what was precious to them and what they were grateful for. They explored what they liked about their body and personality, and find the moment when they were grateful to themselves.

In the sixth session, the goal was to understand, sympathize with other people's minds, and to know and practice how to be a good friend. In the introduction part, through the video "The Power of WordsThank You and the Secret of Annoying," they shared their thoughts on words of gratitude, looked for moments of gratitude to friends, and wrote post-it gratitudes. They were able to find efforts to be good friends by thinking about what their favorite friend looks like from a friend's perspective and writing a list of the most important characteristics of good friends through each other's perspective.

In the seventh session, the goal was to understand, sympathize with other people's minds, and know and practice how to be a good friend. In the introduction part, they tried to find a way to become a great friend through the video of 'How to be a friend in class 2 of 4th grade'. They tried to read the picture book 'When Sophie is angry, When She is really angry' together, explored the conflict, and reflected it 
in their lives. They searched for conflict situations with friends, found more positive conversation methods through the positions of Use oneself and the other party, and stories of other members, practiced the positive conversation methods they found, and practiced them in their daily lives.

In the eighth session they aimed to find gratitude around them, find family's strengths, and find what they can do to contribute to their families' happiness. In the introduction part, they watched the "Power of Positiveness" video, shared gratitude, thought about the moment of gratitude to themselves and the objects around them, and expressed gratitude. In addition, after drawing their family members in the family frame, each member was able to find strengths and attach titles.

In the ninth session, they continued their goal from the eight session in finding strengths among the family and what they can do to contribute to their families' happiness. In the introduction part, they watched the video "Thank you nevertheless," explained gratitude and various types of families, and talked together. They were asked to introduce themselves from the perspective of the selected parents, what they had in common with the eraser clay, and who among their parents knew them best. In addition, they were asked what was the most difficult task for parents and how through their own practical tasks can they become a happier family than they are now.In the 10th session, we were grateful to those who helped us grow, looked back on ourselves from the perspective of the teacher, and aimed to create a positive relationship with the teacher. In the introduction part, we watched the video of "True Love of a Teacher Who Can Change a Child's Life" and shared our thoughts on gratitude. we thought about the help we received from the teacher who helped us grow in detail and wrote a thank-you letter. Finding the strengths of our class, what teachers and they often say, and the definition of our class were made possible.

In the eleventh session, they continued their goal from the tenth session. In the introduction part, they watched the video of Helen Keller, thought about what choice they would make if they were given the three days to talked with Helen Keller when Helen Keller and Sullivan became teachers to share their feelings about each other's roles. In addition, from the teacher's point of view, they were able to introduce themselves, find the characteristics of students they liked and disliked, and practice them through their own practical tasks to become a happy class.

In the twelfth session, the program was wrapped up, the audit continued, and the sessions were completed. In the introduction part, they watched the video of "Surprising Changes in Positive Endstage Cancer Patients" and shared the audit. After recalling the object they were grateful for during the program, they were asked to convey their gratitude. Through the session, they searched for trivial things to thank themselves, encouraged and supported oneself through self-gifts, and congratulated and supported themselves.

\section{Narrative Analysis}

The effectiveness of this program can be confirmed in more depth through narrative analysis. This narrative was organized through the activity sheets of each session after obtaining the parental consent of the participating children.

\subsection{Conditions for being Thankful}

Through the video titled "The Conditions of Thank," the participants understood the audit, formed a rapport, and looked for their own appearance that would change after completing the audit promotion program and their own efforts to achieve such goals. After completing the program, they expressed the expectation that they would become happy persons by appreciating the people around them. 


\subsection{Share Thanks}

Through the video of Nick Vujicic, they learned how to express gratitude, looked beyond physical defects, made positive humor, and looked into Nick Vujicic's mind on how he appreciated his body. Most of their experiences of helping someone include handing over friends' shoes, helping them solve difficult problems, helping them study, helping friends having difficulties, running chores and errands for families, and disinfecting injured friends. In order to better express the reason why audit is not well expressed, they tried to understand true audit by looking at the method.

\subsection{Finding Thanks Out of Optimism}

They found their representative strengths and learned how to think optimistically to recognize themselves positively. In the process of expressing the degree of gratitude, they wrote a relationship map surrounding oneself, recalled the moment, and felt grateful. To make gratitude a part of their lives, they began searching and being thankful for their own strength, and gradually expressed gratitude for the strength of their family members and friends. At the beginning of the program, the members responded sensitively to unexpected behaviors and showed a conflict situation, but it seemed to purify their emotions by finding appreciation through the relationship map surrounding them. In order to learn about each other in everyday life and express gratitude, a notepad called "Thank you" was created so that members could practice and express their gratitude in detail once a week.

\subsection{Words of Thanks}

They understood their feelings, learned how to express them in language, and proceeded to have a positive conversation. After selecting an emotion card and explaining their chosen emotion with gestures, facial expressions, and words, the other person will understand the emotion in the process of guessing. In the words expressed in gratitude, they realized true forgiveness through a video of forgiveness, and after watching the video, they listened to the persons who disappointed them and took the courage to write a letter of forgiveness. In addition, they looked at the feelings where peer relations seemed to have a positive and negative effect on their lives. Above all, they looked for ways to understand themselves by understanding their emotions and to express them more healthily when delivering them to others. In order to know what was good about forgiving someone who gave them a hard time, and to build a good relationship in the future, they thought about what forgiveness is, and wrote a letter of forgiveness.

\subsection{Emotions of Gratitude}

An audit promotion program was conducted so that they could understand their feelings. learn how to express them in language, and have a positive conversation. In expressing gratitude, they were more aggressive in finding the best part of their body. However, upon finding their best personality, they frequently encountered negative stories from others and a negative self-image, and as a result, they said their personality was bad. However, as the session progressed, they reexamined their personality and showed willingness to express gratitude in more detail.

\subsection{Language of Encouragement}

In expressing words of encouragement, they thought of their favorite friend and responded positively. In particular, they expressed their gratitude to friends who listened their story of being bullied. They 
were more serious in making a list on how to be good friends with the community where they live in and they tried to find something practicable to be such good friends.

\subsection{Resolving Conflicts with Your Heart}

A self-encouragement program was conducted to understand, sympathize with other people's minds, and to know and practice how to become good friends. In schools and local children's centers, they wrote down large and small conflict situations on the ground, looked at their mood, and understood the actions of the people who disappointed or hurt them. At first, however, rather than understanding them, it seemed that their emotion was contained. Gradually, most expressed their desire to understand them, apologized to themselves, understood that their feelings were one-sided, and demanded an unconditional apology. By role playing, they put themselves in the situation of the others, created a conversation, searched for positive conversation methods themselves, read the other person's mind and actions, and expressed their minds honestly.

\subsection{Power of Encouragement}

With the power of encouragement, they thought about their encouraging moments and their surroundings and encouraged their bodies to live healthily. They considered the encouraging objects around them and spoke words of encouragement so that other children can expand their encouragement even in small situations. In particular, children from single-parent families can also see stories about their environment and their shrunken self, and in this way, they can see them comforting themselves. In addition, the participants were passive when finding their parents' strengths, but they found encouragement and support in detail while doing some activities they could and expressed their feelings.

\subsection{Practice Encouragement with Your Family}

They tried to act as parents and introduced themselves. However, the people who knew them best were their parents. Through the session's activity, they were asked about their thoughts on a family full of love, a family precious to each other, a happy family, and a good family that does not say hurtful words. They said, "It makes the family laugh. It doesn't make a brother cry." Efforts should be made to practice throwing away trash, applying medicine to mothers, closing doors gently, reducing cell phones, eating a lot, and studying well.

\subsection{Writing a Letter with Encouragement}

The self-encouragement program was conducted to remember those who helped grow from childhood, look back on themselves now, and to have a positive relationship with others. They wrote letters of encouragement and gratitude for themselves and others who helped them, including the teachers they met while growing up.

\subsection{Forming a Relationship of Encouragement}

Forming a relationship with encouragement values family and friends who have helped one's growth and puts their heart into it and delivers it through action in language. In addition, they checked their current appearance by expressing themselves through others. It can be expected that a positive relationship can be formed by practicing specific activities in which children can do something for the class with their teachers. 


\subsection{Change of Encouragement}

The change of encouragement allowed them to find their most grateful objects at the local children's centers, schools, and homes. They wrote their gratitude, specific expressions, and saw happy images beyond seriousness. The object of encouragement can be extended to people around them, their relatives, and friends who have not been in contact for a long time. Through this, it is possible to practice activities to encourage oneself that local children's centers are satisfied rather than resent their families with poor environments.

\section{Effectiveness of Self-encouragement Program}

\subsection{Effects of Peer Relationships}

Through this self-encouragement program, the effects in the peer relationship area of low-income children are as follows.

In the second session, one participant said, "when I helped someone, the other person expressed gratitude, so I wanted to help others more than myself". In the third session, he was somewhat passive when finding his strengths, but when his friends found his strengths together, he used the expression "This is also a good thing." Other friends had a more positive influence by finding advantages that they had not yet perceived.

In the fourth session, they were able to understand each other's positions through situations or events that upset them, such as when parents favored the others, when they talked behind the scenes, when they were angry and teasing each other.

In the sixth session, a participant said, "I looked at myself reflected in my friend's eyes through my friend's perspective." Through the list of good friends, he told his favorite friend that he wanted to remain a good friend, and looked for ways to practice to become such a friend.

In the ninth session, he thought about what he had to do to make his family happy and specifically found ways to help his family. In the 11th session, he became a homeroom teacher, introduced himself, and expressed his understanding of the teacher by expressing why he showed such an attitude from the teacher's point of view in areas that he usually felt unfair. He showed a desire to be recognized by the teacher, and to satisfy that desire, he tried to think more objectively and make efforts for positive changes by writing a list of favorite students from the teacher's point of view. From the perspective of the homeroom teacher, the way to help the class is to say right things, be right in detail, make concessions, be considerate, and serve to pick up trash.

\subsection{The Effect of Curiosity}

The effects of the curiosity area of participants in the self-encouragement program are as follows.

In the second session, a participant answered, "I explored the experience of helping someone, the expression of the other person who received the help, and the feeling and encouragement of the other person. In order to better express the reason why encouragement is not expressed, I understood true encouragement by looking at various methods of expressing encouragement. In the area of curiosity, I watched videos of each session and shared the contents to help understand encouragement from the first to twelfth sessions." Through sharing, he said that encouragement can be encouraged not only by receiving something grandiose, but by existence alone. Looking at the stories of the main characters living happy lives even in poor conditions, he also expressed his expectation that he would be happy like them if the self-encouragement program ended and encouragement became commonplace. 


\subsection{Effectiveness of Emotional Control}

The effects of emotional control are as follows.

In the first session, through conditions of encouragement, people who walk are cyclists, and people who ride bicycles are cyclists. People with physical disabilities envy people who walk. When they were encouraged to live in their current lives, they found encouragement in their environment, such as encouraging their divorced parents to live together or communicate despite not having a cellphone. In the second session, the examined their gratitude for their body and feelings for others through Nick Vujicic's video, where at first, they laughed at the actions of Nick Vujicic, but gradually became serious about what and expressed their gratitude. In the third session, they watched the video of Choi Sungbong who was abandoned by his parents at the age of three and grew up in an orphanage, did not let go of hope through a life equivalent to homelessness, and worked as an opera singer and vocalist. By looking at the protagonist, they expressed encouragement to their lives. In the fourth session, they listened to the story of a grandmother at a noodle restaurant who forgives people who eat and run away without money, and at first, the did not seem to understand the grandmother, but later applauded and rejoiced at the story of turning anger and despair into hope. They also said they could forgive those who hurt them.

In the fifth inning, they said that they could do anything harder and more enjoyable because they were uncomfortable through Lena Maria, so they expressed that they would be able to do better with a little more effort.

In the sixth session, they said that they should practice good words through contradictory words to Bob, and added their experience of experimenting with water.

In the seventh session, they said they were more grateful to a friend who stood by their side while being bullied. In the eighth inning, they said they wanted to live happily through the fact that they could be happy or unhappy depending on their attitude towards the same situation. In the ninth session, they watched a video about Park Ha-neul (pseudonym) who passed medical school by self-taught using the difficult situation, that is, crisis, as an opportunity after the divorce of his parents. Looking at his life, they expressed their encouragement that there are institutions around them that help and take care of their studies. In the tenth session, the expressed their gratitude to the teachers who treated autistic children, supported them in the process of growing up, and shared their hearts. In the eleventh session, they watched a video where Helen Keller said, "If I were given three days, I would like to encourage and thank my family, meet my friends, watch YouTube, listen to the sounds of nature, talk to friends, listen to dogs, say thank you to my family, and watch myself again." In the twelth session, they watched a video about Kim Ga-eul (pseudonym) who was sentenced to a time limit for malignant breast cancer in her early $20 \mathrm{~s}$, but she shed tears at the story that she overcame unbearable pain with only positive power and thought how encouraging she was.

\subsection{The Effect of Optimism}

The effects of optimism are as follows.

In the first session, they expected a positive appearance, such as a happy person, a pleasant person, and a very proud person, and expressed that they should develop a habit of encouraging people around them to achieve such goals. In the third session, encouraging parents made them realize that they are precious, provided with a safe environment, and encouraged in the family itself. In order for encouragement to become a part of life, they expressed more specifically the self-encouragement, gradually the encouragement among their families, and the encouragement among their friends through their own search process. During the second to twelfth sessions, they wrote a detailed note of encouragement for three children living together at local children's centers weekly. In the second and 
third sessions, they used slang or wrote jokes and expressed their feelings, but as the session progressed, they were curious about self-encouragement, and actively found themselves encouraging other children.

\subsection{Emotional Support Effect}

The effects of emotional support are as follows.

In the second session, a participant said, "I looked for ways to express encouragement well through the expressions of encouragement I received and the emotions I felt at that time." He said he wanted to express his honest feelings with thanks and facial expressions. In the fourth session, through the emotion card, he understood his feelings and looked at the emotions and reasons he feels now, especially when he feels the best, he feels joy, happiness, excitement, pride, and comfort. He also said, "when I feel the worst, I'm annoyed, worried, scared, frustrated, scared, and angry." It occurred in relationships with friends and family, and the reasons for such feelings were examined and expressed in detail. In addition, emotions were naturally expressed using media familiar to them. Through the forgiveness video, they felt that they could forgive the objects who made them feel disappointed, and furthermore, they wrote a letter saying that they forgave the object, and through such a process, they expressed that they felt more comfortable. In the fifth session, they encouraged their body to be healthy only. One participant said, "Wow, I only thought about it in my head, but with this session, I showed my willingness to express my encouragement in more detail and try to put it into action."

\subsection{Evaluational Support/Information Support/Material Support Area}

First, the effects of evaluative support are as follows.

In order to understand other people's minds in the sixth session, they first thought about the moment when they encouraged their friends for a week at the local children's center. They looked for good reasons for the friends they chose, and based on this, they wrote a list of good friends, friends who do not tease, friends who do not get angry, friends who help, friends who do not curse, friends who do not bully, and friends who do not ignore even if they do not study. In addition, they thought and responded positively of their favorite friends. In particular, they expressed their gratitude to their friends who listened to their current bullying story.

Second, in the area of informational support during the seventh session, they expressed that a good friend do not to use bad words, are is to hang around with, listens to one's heart, and considerate. It was expressed in the back. By thinking about the conflict situation with friends and listening to the stories of other members, they examined the situation more objectively. Based on this, they said that they wanted to keep their promise to their efforts of becoming a good friend, demonstrating and practicing expressing their thoughts in concrete words, such as "I hope you don't get annoyed and tell me why you're angry?"

Third, in the eight session, a participant said, "I thought about the encouraging moments of myself and my surroundings (e.g., watches let me know the time, keep my promise), and encouraged my body to be alive and healthy. When I thought of the encouraging objects among the objects around me and asked them to give words of encouragement, many children expanded the area of encouragement to even small objects." In particular, in the second half, children from rich families were intimidated by talking about examples of their home environment, and many children were not teasing for deficiency, but comforted by saying, "Even if you don't have a mother, you have a father." After hearing that, the child, who seemed somewhat nervous and intimidated by the story, became comfortable. In addition, children at local children's centers were also somewhat passive in finding their mothers' strengths in the beginning, but as the session progressed, they found in detail what their mothers strengths were and expressed their encouragement. In the ninth session, the participant said, "I tried to complete it using 
eraser clay, recalling the object that parents know and talk about the best." Due to the nature of the eraser clay, it was a bit difficult to make it soft using the warmth of the palm, but most children said that it would have been difficult for their parents to give birth to them. With encouragement, they said they would be happy by looking for various ways to practice making their families laugh, no to make their younger siblings cry, listen to their parents well, and study well. In the tenth session, they thought of the teacher who helped them grow and conveyed their hearts through a letter of encouragement. They wrote a letter of encouragement for the experiences they had with their teachers, for teaching them, for speaking kindly for six years, for helping them when they wanted to give up everything, when they were discriminated, for telling stories, and for receiving their help. Move to first paragraph of the conclusion section.

\section{Conclusion}

Participants of the self-encouragement program were effective in self-resilience and social support to cope more healthily in stressful situations. In other words, the more social support they received through the self-encouragement program, the more they felt psychologically comfortable.

This study is about expressing heart of encouragement not only for emotional support but also for learning achievement through learning assistance. In this way, the study analyzed the effects of selfencouragement programs such as self-elasticity, subjective well-being, and social support through the participants' narratives. Focusing on the research results derived in this study, the conclusions are as follows.

First, the self-encouragement program renewed the perception of encouragement for low-income children in local children's centers, recognized the need for encouragement, and helped to increase the tendency of encouragement by using encouragement as a way of converting positive thinking. Second, the self-encouragement program helped low-income children's self-resilience, subjective well-being and social support. Third, the self-encouragement program helped the children to be satisfied with one's life, acquire positive emotions, and reduce negative emotions. Fourth, through the self-encouragement program, low-income children recognized themselves, family members, friends, and teachers as objects of encouragement and had an active encouragement attitude, which helped them to self-encourage children.

Suggestions and limitations according to the conclusion are as follows.

First, since this study targeted low-income children, it is necessary to develop a self-encouragement program suitable for each age for younger and higher ages. Furthermore, various self-help programs are needed, such as parents and children, teachers and students together.

Second, since it was conducted 12 times for one hour only for low-income children, there is a limit to generalizing its effectiveness. This study obtained positive effects by conducting 12 sessions distributed for 12 weeks, but it is necessary to supplement the research results by comparing persistence with the effects of long-term programs.

This study has limitations such that the results cannot be generalized because they were drawn from a limited number of study participants. In addition, if research participants with various backgrounds are selected and studied in the future, a more systematic and effective program can be derived.

\section{References}

[1] B. R. Han, The effects of the Gratitude Education Program on Elementary school Students' Subjective Well-being and Psychological maladjustment, Graduate School of Education, Seoul National University of Education, Master's Thesis, pp.6-12, (2013) 
[2] S. H. Kang, The mediating effect of personality strength on the relationship between perceived social support and subjective well-being by children: Focused on the regional child center, Sangmyung University Graduate School of Welfare Counseling, Master's Thesis, pp.7-18, (2013)

[3] K. H. Kim, Korea Child's Right to Live: The actual conditions and Change of Poverty, Family, Environment, Safety and Health, Journal of Korean Council for Children \& Rights, (2010), Vol.14, No.1, pp.1-39, UCI: G704000427.2010.14.1.005

[4] S. H. Lee, J. Y. Park, Y. H. Kim, Y. E. Chang, S. Y. Auh, The Effects of Perceived Family Strength and Ego-Resilience on the Adjustment of Children from Low-Income Families to School, Journal of Families and Better Life, (2009) Vol.27, No.2, pp.305-316, UCI: G704-000320.2009.27.2.015

[5] N. R. Gum, The impact of the audit promotion group program on the auditor's tendency and emotional experience of institutionalized children, Pusan National University, Master's Thesis, pp 7-13, (2015)

[6] M. G. Kim, A Study on the Effect of Writing a Thank You Diary on Promoting Happiness, Graduate School of Education, Daegu National University of Education, Master Thesis, pp.10-17, (2018)

[7] G. H. Kim, The Effect of Audit Note Writing Activity on Adolescents' Auditing Tendency and Psychological Wellbeing, Ewha Womans University, Master Thesis, pp.9-14, (2014)

[8] Y. S. Moon, Effects of the Physical Audit Meditation Program on Self-esteem and Self-concept Improvement in Adolescent Girls, Graduate School of Education, Nambu University, Master's Thesis, pp.10-18, (2005)

[9] D. Y. Park, The Effects of Audit Diary Group Counseling on Elementary School Students' Self-Efficacy and Interpersonal Relationship, Graduate School of Education, Korea University, Master's Thesis, pp.6-15, (2013)

[10] J. Y. Park, M. N. Lee, Developing an audit promotion program using picture books, Asia-pacific Journal of Multimedia Services Convergent with Art, Humanities, and Sociology, (2018), Vol.8, No.9, pp.441-449, DOI: 10.35873/ajmahs.2018.8.9.044

[11] S. J. Yoo, Development and Validation of Audit Education Program for Improving Happiness and Depression of High School Elementary School Children, Seoul National University of Education, Master Thesis, pp.8-16, (2011) 